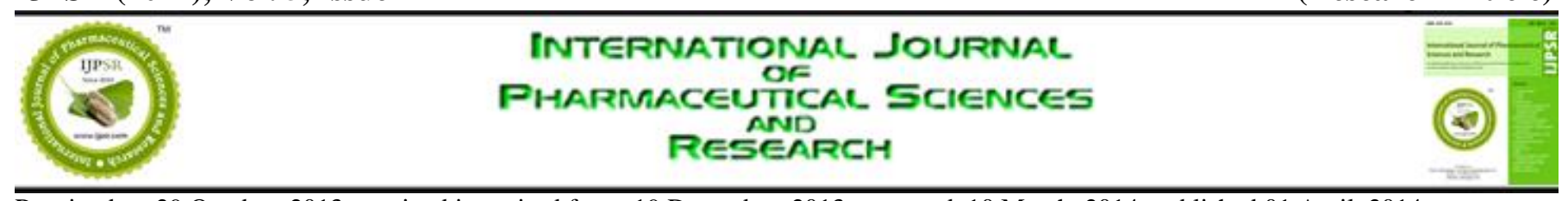

Received on 29 October, 2013; received in revised form, 19 December, 2013; accepted, 10 March, 2014; published 01 April, 2014

\title{
CUTANEOUS LEISHMANIASIS IN SYRIA
}

Idriss Sara* $^{1}$, Abdulkader Rahmo ${ }^{2}$ and Mohammad Maarouf ${ }^{1}$

Biochemistry and Microbiology, Faculty of Pharmacy, Damascus University ${ }^{1}$, Damascus, Syria Medical Biotechnology Department, National Commission for Biotechnology ${ }^{2}$, Damascus, Syria

Keywords:

Cutaneous leishmaniasis (CL), PCRRFLP, iternal transcribed spacer 1 (ITS1), multilocus microsatellite typing, Syria

Correspondence to Author:

Idriss Sara

Biochemistry and Microbiology, Faculty of Pharmacy, Damascus University, Damascus, Syria

E-mail: idriss_sara@yahoo.com
ABSTRACT: Cutaneous leishmaniasis (CL) is a public health problem in Syria call for this parasite's epidemiological and evolutionary investigation. Evaluation of its population structure by multilocus enzyme electrophoresis (MLEE), current gold standard for classification, has some drawbacks, such as the lack of discriminatory power below species level, it is labour intensive and time-consuming. In this study, MLEE has been replaced by applying PCR-RFLP of the internal transcribed spacer 1 (ITS1) for identification of leishmania at species level, on 37 samples were obtained from patients with suspected CL referred to Damascus Dermatology Hospital, 19 of them from Damascus and 18 from Aleppo. Intraspecific variation could be detected by the use of 9 hypervariable microsatellite markers. Our results showed that all samples were $L$. tropica. 26 genotype were detected, of wich 20 were unique to individual strains and 6 were shared by more than sample. Results also showed that there was amoderate genetic differentiation and a clear genetic flow between Aleppo and Damascus. In conclusion, in the present study, the first molecular method for typing leishmania Syrian strains was put, and for the first several epidemiological questions linked with Syrian stains could be addressed.
INTRODUCTION: Protozoan parasites in the genus Leishmania, transmitted to humans and other vertebrate host through the bite of sand fly vectors, are the causative agents of a spectrum of human diseases collectively known as leishmaniasis ${ }^{1}$. Leishmaniasis can vary from a chronic skin ulcer, to erosive mucosal disease with progressive destruction of the nasopharynx and severe facial disfigurement, to a life-threatening systemic infection with hepato-splenomegly ${ }^{2}$.

\begin{tabular}{|c|c|}
\hline \multirow[t]{2}{*}{ QUICK RESPONSE CODE } & $\begin{array}{c}\text { DOI: } \\
\text { 10.13040/IJPSR.0975-8232.5(4).1362-66 }\end{array}$ \\
\hline & $\begin{array}{l}\text { Article can be accessed online on: } \\
\qquad \text { www.ijpsr.com }\end{array}$ \\
\hline : http://d & 13040/IJPSR.0975-8232.5(4).1362-66 \\
\hline
\end{tabular}

There are about 1.5 million new cases of cutaneous leishamaniasis each year of which more than $90 \%$ occur in Afghanistan, Algeria, Iran, Iraq, Saudi Arabia and Syria, in the 'Old World', and Brazil and Peru in the 'New World' ${ }^{3,4}$. Syria was facing major increase in the number of registered cases to reach 58156 cases of CL in the year 2011 putting the country as the top rank among the highest countries of registered cases in the Mediterranean region 5 .

The current classification of leishmania is still based on isoenzyme typing by using multilocus enzyme electrophoresis (MLEE). MLEE has some limitations. It is expensive, slow and laborious, and it is not easy to compare the raw data from different laboratories. The need of mass in-vitro culture makes it unsuitable for high throughput analyses. 
A major disadvantage is that it determines phenotypes and not genotypes. In addition, any nucleotide substitution that does not change the amino acid composition remains undetected, and the same is true for changes in the amino acid composition that do not influence the electrophoretic mobility. Another disadvantage is that the house-keeping genes analysed in MLEE are most probably under selective pressure so that mutations observed are not neutral ${ }^{6,7,8}$.

The discriminatory power of MLEE for classifications below species level is limited 9 . Numerous PCR approaches have been published based on different coding and non-coding regions in the Leishmania genome useful for identification at species level. Approaches based on initial amplification of genus-specific sequences followed by subsequent differentiation of leishmania species by restriction fragment length polymorphisis RFLP, hybridization with specific probes or sequencing of the amplified sequences have proven most useful ${ }^{9}$.

Different targets have been used for this such as the ribosomal internal transcribed spacer ${ }^{10,11}$, the miniexon ${ }^{12}$, hsp 70 genes ${ }^{13}$, cytochrome b gene ${ }^{14}$ and 7SL RNA gene sequences ${ }^{15}$. ITS1 is the most widely used assay for direct detection and identification of Leishmania species in the Old World ${ }^{9}$. Epidemiological studies require a high resolution molecular-typing method to distinguish between closely related strains. Several molecular typing methods have been developed to improve the discriminative power of typing methods for the genus Leishmania below species level. These include amplification of parasite DNA sequence by either a specific PCR or a random amplified polymorphic DNA (RAPD) PCR or detection of restriction fragment length polymorphisis (RFLPs) by southern hybridization with DNA-specific probes ${ }^{16,17}$.

RFLP analysis is a time-consuming technique and large amounts of purified DNA are needed, whereas RAPD analysis requires strict conditions to obtain reproducibility between different laboratories and generates complex patterns. In contrast, specific PCR-based methods are attractive because of their rapidity and because culturing parasites can be avoided ${ }^{18}$. Microsatellite sequences are repeated motifs of 1-6 nuceotides found in all eukaryotic and prokaryotic genomes.
Analysis of length polymorphisims of microsatellite-containing sequences has, recently become an important tool for population and genetic studies of many species including humans. Microsatellite sequence variation results from the gain and loss of single repeat units, which can easly detected after amplification with primers annealing specifically to their flanking regions. The results of these analyses of multilocus microsatellite typing (MLMT) are theoretically reproducible and exchangeable between laboratories. Selection does not seem to act on polymorphisms in microsatellite length, and allele variants are detectable because of the co-dominant nature of these markers ${ }^{9}$.

\section{MATERIALS AND METHODS:}

Patients and samples: 37 samples were obtained from patients with suspected CL referred to Damascus Dermatology hospital between 20092010. 19 of them were from Damascus and 18 from Aleppo. Each sample was examined through microscopic examination to confirm case of CL, by scraping the internal border of skin lesions with asurgical blade. Sample was fixed with $100 \%$ methanol and stained with giemsa for microscopy.

Parasite culture and DNA preparation: Parasite promastigotes were maintained in Novy-NicolleMcNeal medium followed by incubation at $26^{\circ} \mathrm{C}$ and microscopically observed every 3 days for 4 weeks before they were reported as negative. If the culture were positive for mass production, the growth promastigotes were run in RPMI-1640 supplemented with $10 \%$ fetal calf serum, $100 \mathrm{ug} / \mathrm{ml}$ penicillin, and $100 \mathrm{ug} / \mathrm{ml}$ streptomycin. Parasites were harvested in the late log phase, washed 3 times, and kept at $-80^{\circ} \mathrm{C}$ for PCR.

ITS1-PCR-RFLP: DNA was extracted from culture promastigotes by QiAmp blood Minikit (QIAGENE, Germany). Small subunit (SSU) ribosomal RNA (rRNA) and 5.8S rRNA regions that are related to ribosomal ITS1 were amplified using the primers LITSr (5'CTGGATCATTTTCCGATG-3') and L5.8s (5'TGATACCACTTATCGCACTT-3') Fermentas, Life Science, Germany). Amplification of the DNA was performed in a 50-uL reaction composed of $1 \mathrm{x}$ PCR buffer, $0.2 \mathrm{mM}$ dNTPs, $1.5 \mathrm{mM} \mathrm{Mg}^{+2}, 0.1$ U/uL of Taq polymerase (Euroclone, Genomic) $1 \mathrm{uM}$ of each primer, and $5 \mathrm{uL}$ of DNA from culture isolates. 
The PCR products were digested with HaelII enzyme (Fermentas, Life Science, Germany) and its related buffer at $37^{\circ} \mathrm{C}$ overnight. Amplification stages were as follows in Mastercycler (GermanyEppendorf): initial denaturation at $95^{\circ} \mathrm{C}$ for 2 minutes was performed, followed by 42 cycles of $95^{\circ} \mathrm{C}$ for 20 second, $53^{\circ} \mathrm{C}$ for 30 second, and $72^{\circ} \mathrm{C}$ for 1 minute, with an additional $72^{\circ} \mathrm{C}$ for 6 minutes for post-extension. Fragment size analysis by polyacrylamide $12 \%$ gel.

Microsatellite genotyping: microsatellite analysis was performed using 9 microsatellite markers developed for $L$. tropica and L. donovani (table 1). The PCR mixture contained 1x PCR buffer, $0.2 \mathrm{mM}$ dNTPs, $1.5 \mathrm{mM} \mathrm{Mg}^{+2}, 0.1 \mathrm{U} / \mathrm{uL}$ of Taq polymerase
(Euroclone, GENOMIC), 1uM of each primer (Fermentas, Life Science, Germany), and 20 ng of genomic DNA from culture isoltes. Initial denaturation at $94^{\circ} \mathrm{C}$ for 2 minutes was performed, followed by 35 cycles of $94^{\circ} \mathrm{C}$ for 30 second, the specific annealing temperatures are listed in Table 1 , and $72^{\circ} \mathrm{C}$ for 2 minutes, with an additional $72^{\circ} \mathrm{C}$ for 5 minutes for post-extension.

Microsatellite amplification and fragment size analysis by polyacrylamide electrophoresis $12 \%$ (Fig. 1). The software Power Marker V3.25 was used to assess the allelic diversity (A). The expected $\left(H_{e}\right)$ and observed $\left(H_{o}\right)$ heterozygosity, inbreeding coefficient $F_{i s}$, fixation index $\left(F_{s t}\right)$ and Analysis of Molecular Variance (AMOVA).

TABLE 1: NINE MICROSATELLITE MARKERS USED IN THIS STUDY

\begin{tabular}{|c|c|c|}
\hline Marker & Primers & Anneling temperature \\
\hline \multirow{2}{*}{ GA2 } & F:GATCACAGCGACGTCTGAAG & \multirow{2}{*}{$56^{\circ}$} \\
\hline & R:CCTGCTGCCACCATCTTAGC & \\
\hline \multirow{2}{*}{ GA11 } & F:GGTCGGGGGGTGTCTTCTCC & \multirow{2}{*}{$54^{\circ}$} \\
\hline & R:CTGCCAGAGAAGGAGAGGAG & \\
\hline \multirow[b]{2}{*}{ GA6 } & F:GTGTGAGCTAATCGATTGG & \multirow{2}{*}{$42^{\circ}$} \\
\hline & R:CGCTCTCTCTGTCTCTGTCT & \\
\hline \multirow{2}{*}{ GT4 } & F:TCTGTGCATCACTCTCGCCA & \multirow{2}{*}{$58^{\circ}$} \\
\hline & R:TGAGTCTGCGGGCGCGCGCT & \\
\hline \multirow{2}{*}{ LIST7039 } & F:CTCGCACTCTTTCGCTCTTT & \multirow{2}{*}{$58^{\circ}$} \\
\hline & R:GAGACGAGAGGAACGGAAAA & \\
\hline \multirow{2}{*}{ 4GTG } & F:CGGTTTGGCGCTGAAAGCGG & \multirow{2}{*}{$58^{\circ}$} \\
\hline & R:CGTGAGGACGCCACCGAGGC & \\
\hline \multirow{2}{*}{ 27GTG } & F:GGAGGTGGCTGTGGTTGTTG & \multirow{2}{*}{$58^{\circ}$} \\
\hline & R:GCCGCTGACGCTGCAGGCT & \\
\hline \multirow{2}{*}{ LIST7036 } & F:CTCTCTCGTCACCACAGCAC & \multirow{2}{*}{$58^{\circ}$} \\
\hline & R:TCCCTCTCGTTGGTGAAGTT & \\
\hline \multirow{2}{*}{ LIST7040 } & F:GCAGAGCGAGACACACAGAC & \multirow{2}{*}{$58^{\circ}$} \\
\hline & R:GTGCACGTTGATGTGCTTCT & \\
\hline
\end{tabular}

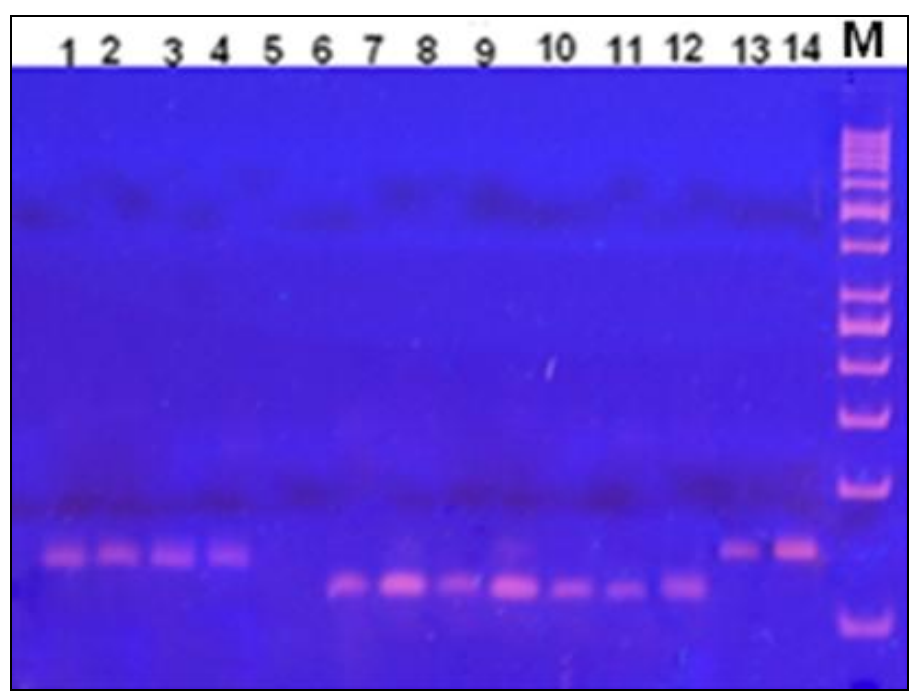

FIG. 1: FRAGMENT LENGTH ANALYSIS BY PAGE; M, 50-BP LADDER 
RESULT: PCR amplification of ITS1 from all isolates yielded fragments of about 350-bp. As a resul of digestion with HaeIII, ITS1-PCR producte yielded 60-bp and 190-bp corresponding with $L$. tropica. 26 different genotypes were detected among the 37 stains of L. tropica analysed, of which 20 were unique to individual strand and 6 were shared by more than on strain. Analysis of 26 genotypes revealed a number of allelic variant (A) that varied between 2 (LIST7036) and seven (GT4), with average of 5.3 per locus (Table 2). The observed heterozygosity $\left(H_{0}\right)$ ranged from zero to 0.647 , indicating the presence of both homozygotic and heterozygotic loci in the population.

The expected heterozygosity $\left(H_{e}\right)$ as a measure for genetic diversity ranged from 0.74 to 0.49 and was generally higher than the mean observed. The inbreeding coefficient per locus revealed positive values, indicating a large number of homozygotes in the population. Fst, as a measure for genetic differentiation between populations, was calculated (Table 3). It was 0.125 between Aleppo and Damascus. AMOVA is based on the calculation of a genetic distance matrix using a selected distance metric and assesses the variance apportioned within and between predefined groups. AMOVA results supported a low amount of differentiation $28.02 \%$ between the two populations Aleppo and Damascus, and $71.98 \%$ of the variation was due to the variation within the two populations. $10.25 \%$ was within Damascus population and $61.73 \%$ was within Alepo population (Table 4).

TABLE 2: GENETIC CHARACTERISTICS AND VARIATION OF THE 9 MICROSATELLITE LOCI DETECTED IN THE POPULATIONS OF LEISHMANIA TROPICA. A, number of alleles; $H_{e}$, expected heterozygosity; $H_{0}$. Observrd heterozygosity; $F_{i s}$, inbreeding coefficient.

\begin{tabular}{ccccc}
\hline Marker & $\mathbf{A}$ & $\boldsymbol{H}_{\boldsymbol{e}}$ & $\boldsymbol{H}_{\boldsymbol{0}}$ & $\boldsymbol{F}_{\boldsymbol{i s}}$ \\
\hline GA2 & 6.0000 & 0.7411 & 0.3243 & 0.5716 \\
GA11 & 6.0000 & 0.7297 & 0.3243 & 0.5650 \\
GA6 & 6.0000 & 0.6928 & 0.3243 & 0.5416 \\
GT4 & 7.0000 & 0.7129 & 0.3784 & 0.4799 \\
LIST7040 & 4.0000 & 0.6773 & 0.6471 & 0.0596 \\
LIST7039 & 6.0000 & 0.5895 & 0.3784 & 0.3700 \\
4GTG & 6.0000 & 0.6954 & 0.4054 & 0.4283 \\
27GTG & 5.0000 & 0.6245 & 0.2703 & 0.5765 \\
LIST7036 & 2.0000 & 0.4965 & 0.0000 & 1.0000 \\
Mean & 5.3333 & 0.6622 & 0.3392 & 0.4984 \\
\hline
\end{tabular}

TABLE 3: ESTIMATES FOR FST, MEASURES OF GENETIC DIFFERENTIATION (ABOVE DIAGONAL), FOR ALL LOCI BETWEEN PREDEFINED POPULATION ACCORDING GEOGRAPHIC REGIONS. Below diagonal is the corresponding calculated migration rate, Nm. D, Damascus; A, Aleppo.

\begin{tabular}{ccc}
\hline & $\mathbf{D}$ & $\mathbf{A}$ \\
\hline $\mathbf{D}$ & 0.00 & 0.12 \\
$\mathbf{A}$ & 1.8 & 0.00 \\
\hline
\end{tabular}

TABLE 4: AMOVA FROM TWO POPULATIONS USING 9 MICROSATELLITE MARKERS

\begin{tabular}{cccc}
\hline Locus & Source & $\begin{array}{c}\text { Sum of } \\
\text { Square }\end{array}$ & Percentage \\
\hline Overall & Among Populations & 29.9986 & 0.2802 \\
Overall & Within Population (D) & 10.9683 & 0.1025 \\
Overall & Within Population (A) & 66.0875 & 0.6173 \\
Overall & Total & 107.0543 & 1.0000 \\
\hline
\end{tabular}

DISCUSSION: In the past decades, DNA-based molecular techniques have improved the identification of Leishmania parasites at both the species and strain levels. Study of the species and strains distribution can help us to design prophylactic strategies for disease control and preparing an effective vaccine based on strains. So these informations can be used for ecologic, clinical, and epidemiologic studies. In this present study, we made protocols accurately to detect Syrian Leishmania species and strains. Results showed that ITS1-RFLP from all isolates yielded as L. tropica.

After species diagnosis we report the isolation of 9 microsatellite markers for investigating the population genetic and epidemiology of the $L$. tropica between Aleppo and Damascus populations. Once the population structure is defined, $F$-statistics are of high value for population studies of diploid organisms including Leishmania. $F$ is, a measure of the inbreeding of individuals resulting from the deviation from panmixia, and Fst, a measure of relatedness between individuals due to the structure of the population, provide information about the mode of reproduction and population differentiation ${ }^{19}$.

Clonal diploids are expected to accumulate heterozygosity over time at every locus and should therefore exhibit negative $F_{\text {is }}$ values. Heterozygote deficiency (positive $F_{i s}$ ) seen in this study and many other of leishmania can be due to the presence of different factors, such as population subdivision (Wahlund effect) or to frequent sexual crosses of individuals from same strain 
(inbreeding). The substantial heterozygote deficiency and extreme inbreeding found in this study is not consistent with a strictly clonal reproduction. Fst value showed that there is amoderate genetic differentiation between Aleppo and Damscus according to Wright $1978^{20}$. Fst can also be used to estimate genetic flow or migration rate, $\mathrm{Nm}$, as $\mathrm{Nm}=1-\mathrm{FST} / 4 \mathrm{FST}$.

Genetic flow migration (or gene flow) refers to the movement of individuals among subpopulations and can set a limit as to how much genetic divergence can occur. At the predefined population identification, there was a clear genetic flow (migration rate) between Aleppo and Damscus that suggest transfer of the disease by human activities between two regions. The high diversity of Aleppo strains, as AMOVA showed, that might be related to the age of the focus. In this study, We put the first molecular method for typing leishmania Syrian strains and it exhibits a highly discriminatory power for strains differentiation. It will also help us to answer some epidemiological questions.

Therefore, it is necessary the further investigations with more samples from patient, vectors, and reservoir hosts from different geographic areas in Syria be performed.

\section{REFERENCES:}

1. Bates, A.P., Transmission of Leishmania metacyclic promastigotes by phlebotomine sand flies. International Journal for Parasitology 2007; 37: 1097-1106.

2. Pearson, R.D., and Sousa, A.Q., Clinical spectrum of Leishmaniasis. Clin Infect Dis. 1996 Jan; 22(1): 1-13.

3. Kumar, S, Kumar, R., and Kumar, A., Leshmania donovani: how it makes fool to our immune system. International Journal of Scientific and Research Publications. 2012; 2(9).

4. Postigo, J.A., Leishmaniasis in the world Health Organization Eastern Mediterranean region.Int J Antimicrob Agent.2010, S62-5.

5. Elsheik, K., and Eltaweel, A., Epidemiology of Cutaneous leishmaniasis cases in Syria 2011.syrian epidemiological bulletin.

6. Noyes, H. A., Belli, A. A., and Maingon, R. Appraisal of various random amplified polymorphic DNA-polymerase chain reaction primers for Leishmania identification.
American Journal of Tropical Medicine and Hygiene.1996; 55: 98-105.

7. Jamjoom, M.B., Ashford, R.W., Bates, P.A., Kemp, S.J., Noyes, H.A., Towards a standard battery of microsatellite markers for the analysis of the Leishmania donovani complex. Ann. Trop. Med. Parasitol, 2002; 96: 265-270.

8. Jiménez, M., Alvar, J., and Tibayrenc, M. Leishmania infantumis clonal in AIDS patients too: epidemiological implications. AIDS, 1997; 11: 569-573

9. Schonian, G., Kuhls, K., and Mauricio, I. L. Molecular approaches for a better understanding of the epidemiology and population genetic of leishmania. Parasitology .2011; 138(4): 405-25.

10. Nasereddin, A., Bensoussan-Hermano, E., Schönian, G., Baneth, G., and Jaffe, C.L., Molecular diagnosis of Old World cutaneous leishmaniasis and species identification by use of a reverse line blot hybridization assay. J Clin Microbiol. 2008; 46(9): 2848-55

11. Cupolillo, E., Grimaldi Júnior, G., and Momen, H., Beverley, S.M., Intergenic region typing (IRT): a rapid molecular approach to the characterization and evolution of Leishmania. Mol Biochem Parasitol. 1995; 73(1-2): 145-55.

12. Harris, E., Kropp, G., Belli, A., Rodriguez, B., and Agabian, N. J., Single-step multiplex PCR assay for characterization of New World Leishmania complexes. Microbiol. 1998; 36(7):1989-95.

13. Fraga, J., Montalvo, A.M., De Doncker, S., Dujardin, J.C., and Van der Auwera ,G., Phylogeny of Leishmania species based on the heat-shock protein 70 gene. Infect Genet Evol. 2010 Mar; 10(2): 238-45.

14. Kato, H., Uezato, H., Katakura, K., Calvopiña, M., Marco, J.D., Barroso ,P.A., Gomez, E.A., Mimori,T., Korenaga, M., Iwata, H., Nonaka, S., and Hashiguchi, Y., Detection and identification of Leishmania species within naturally infected sand flies in the Andean areas of Ecuador by a polymerase chain reaction. Am J Trop Med Hyg. 2005 Jan; 72(1):87-93.

15. Zelazny, A.M., Fedorko, D.P., Li, L., Neva, F.A., Fischer, S.H., Evaluation of 7SL RNA gene sequences for the identification of Leishmania spp. Am J Trop Med Hyg. 2005 Apr; 72(4): 415-20

16. Minodier, P., Piarroux, R., Gambarelli, F., Joblet, C., Dumon $\mathrm{H}$. Rapid identification of causative species in patients with Old World leishmaniasis. J Clin Microbiol. 1997 Oct; 35(10): 2551-5.

17. Ravel, C., Wincker, P., Bastien, P., Blaineau, C., Pagès, M., A polymorphic minisatellite sequence in the subtelomeric regions of chromosomes $\mathrm{I}$ and $\mathrm{V}$ in Leishmania infantum. Mol Biochem Parasitol. 1995 Oct; 74(1): 31-41.

18. Bulle, B., Millon, L., Bart, J.M., Gállego, M., Gambarelli, F., Portús, M., Schnur,L., Jaffe, C.L, Fernandez-Barredo,S., Alunda, J.M., Piarroux, R., Practical approach for typing strains of Leishmania infantum by microsatellite analysis. J Clin Microbiol. 2002 Sep; 40(9): 3391-7.

19. De Meeûs, T., Lehmann, L., Balloux, F., Molecular epidemiology of clonal diploids: a quick overview and a short DIY (do it yourself) notice. Infect Genet Evol. 2006 Mar; 6(2): 163-70.

20. Wright, S. (1978). Evolution and the genetics of natural populations, vol 4. Variability within and among natural populations. University of Chicago Press, Chicago.

How to cite this article:

Sara I, Rahmo A and Maarouf M: Cutaneous Leishmaniasis in Syria. Int J Pharm Sci Res 2014; 5(4): 1362-66.doi: 10.13040/IJPSR.0975-8232.5(4).1362-66

All @ 2013 are reserved by International Journal of Pharmaceutical Sciences and Research. This Journal licensed under a Creative Commons Attribution-NonCommercial-ShareAlike 3.0 Unported License.

This article can be downloaded to ANDROID OS based mobile. Scan QR Code using Code/Bar Scanner from your mobile. (Scanners are available on Google Playstore) 